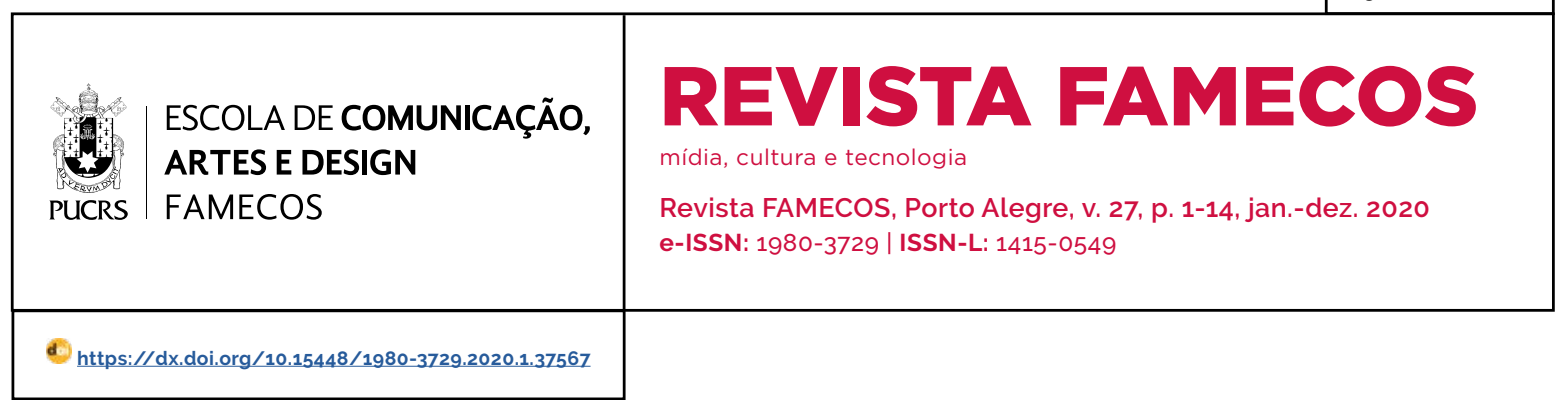

AUDIOVISUAL

\title{
O dispositivo confessional no documentário e os seus efeitos
}

The confessional device in the documentary and its effects

El dispositivo confesional en el documental y sus efectos

\section{Gilberto Alexandre \\ Sobrinho ${ }^{1}$ \\ 0000-0002-5083-384X \\ gilsobrinho@iar.unicamp.br}

Recebido em: 3/4/2020.

Aprovado em: 7/11/2020.

Publicado em: 22/12/2020.
Resumo: O artigo aborda o ato da confissão em filmes e videos documentários. Trata-se de um falar de si para dispositivos de gravação de imagem e som, em uma relação dúbia de espelho e janela. Refletimos sobre as várias formas de ativação e atualização desses recursos, voltadas para as construções de identidades e de subjetividades, ensejadas por relações de conhecimento e de poder. O texto inspeciona algumas dessas formas em documentários brasileiros e destaca o sentido da performance confessional, como aspecto dominante.

Palavras-chave: Dispositivo confessional. Identidade e subjetividade. Documentário brasileiro. Performance confessional

Abstract: The article approaches the act of confession in film and video documentaries. It is about talking about yourself for image and sound recording devices, in a dubious mirror-window relationship. We reflect on the various forms of activation and updating of these resources, aimed to the construction of identities and subjectivities, driven by relations of knowledge and power. The text inspects some of these forms in Brazilian documentaries and highlights the sense of confessional performance, as dominant aspect.

Keywords: Confessional device. Identity and subjectivity. Brazilian documentary. Confessional performance

Resumen: El artículo aborda el acto de confesión en películas documentales y videos. Se trata de hablar de sí para dispositivos de grabación de imagen y sonido, en una dudosa relación espejo-ventana. Reflexionamos sobre las diversas formas de activación y actualización de estos recursos, dirigidas a la construcción de identidades y subjetividades, impulsadas por las relaciones de conocimiento y poder. El texto inspecciona algunas de estas formas en documentales brasileños y destaca el sentido de la performance confesional, como un aspecto dominante. Palabras clave: Dispositivo confesional. Identidad y subjetividad. Documental brasileño. Performance confesional.

\section{Percursos}

Fala-se de si bastante no domínio do documentário, principalmente depois do surgimento e da disseminação de câmeras e de gravadores portáteis, analógicos e digitais. Essa acentuada falação, que combina desde a espontaneidade da oralidade até a impostação de discursos de autoridade, estabeleceu-se como um dos recursos mais recorrentes entre as estratégias de desenvolvimento discursivo que atualizam os assuntos, temas e propostas de documentários e de filmes-ensaios. Desde o cinema moderno dos anos 1960 e início dos anos 1980, onde 
configura, de forma dominante, os modos do cinema direto/verdade, passando pela emergência do vídeo e as formas contemporâneas híbridas do audiovisual pós-digital, ${ }^{2}$ esses sujeitos e suas falas, em chaves diferenciadas, têm, assim, constituido modos éticos e estéticos nesse terreno tão caro à modelação do real.

Falar e escutar são processos que se operam no mesmo espaço e, assim, como se constituem distintos modos de endereçar-se para a câmera oralmente, também se constituem modos variados de escuta. Bill Nichols (2017) oferece uma sintese contundente desse processo, reiterando os espaços de questionamento como procedimentos éticos/estéticos desdobrados dessas práticas:

Depois de 1960, o plano individual de um sujeito não é mais apenas um fragmento em um processo de montagem. O individuo que está na cena não é mais apenas um exemplo de um princípio maior. Existe a sensação de um encontro pessoal e direto. Perguntas precisas envolvendo a ética do encontro surgem: como nos comportamos na presença dos outros? Tratamos os outros com respeito ou desrespeito, como figuras humanas completas ou como símbolos ou estereótipos à serviço de um propósito maior? A voz do documentário agora nos diz, em tantas palavras: 'É assim que escolho agir e filmar; o que você acha disso? (NICHOLS, 2017, p. 9)

No Brasil, já nos anos 1970 essas mudanças foram parcialmente sentidas. Ainda sob forte influência da crítica à nação, como constitutiva de práticas modernas do audiovisual, observa-se na produção documentária do Globo Repórter, da Rede Globo, dois documentários que, embora não abandonem a dimensão crítica da realidade social como tônica dominante, provocam interessante desvio em relação à dimensão do tratamento da fala de seus personagens, haja visto que na maioria dos documentários os sujeitos se manifestavam, sobretudo, a partir de uma exterioridade marcante, funcionando como elemento ilustrativo do argumento que se desenvolvia, em geral, endereçado às questões sociopoliticas.

Esse deslocamento é sentido, por exemplo, em Retrato de Classe (1977), de Gregório Bacic, e Teodorico, Imperador do Sertão (1978), de Eduardo Coutinho. Em ambos, realizam-se, estrategicamente, narrações de si; no primeiro, um grupo de homens e mulheres de classe média em São Paulo, outrora alunos que formavam parte de uma turma ginasial, em um antigo colégio paulistano, confidenciam sobre suas memórias, frustrações, cotidianos e projetos futuros e, no segundo, um senhor da elite política e econômica do Rio Grande do Norte revela sobre seus modos particulares de articulação política e, também, sobre um campo de relações afetivas e de memórias, o que compõe, por via do retrato intimo um quadro complexo de relações de poder.

No plano profundo, mesmo com esses recursos de atenção às vozes particulares, há, ainda, o expediente da busca pelo desenho crítico da nação. Assim, os documentários apontam para um caminho que será assumido integralmente em produções vindouras, sendo esses filmes ainda encapsulados pela necessidade firme de um posicionamento político, que articulava uma produção interessada em criticar a classe média e seus valores, no caso de Retrato de Classe, e, também, em posicionar-se contra a elite latifundiária, em Teodorico, Imperador do Sertão, ambos documentários arregimentavam recursos de encenação por meio de formas enviesadas contra as políticas da ditatura militar vigente. ${ }^{3}$

Ainda nesse contexto de transição, o filme que encerraria essa fase do cinema moderno, onde "a nação, enquanto categoria orientadora da ação cultural ou política, tinha papel chave" (XAVIER, 2001, p. 25) é Cabra Marcado para Morrer (1984), de Eduardo Coutinho, e aqui, a síntese da experiência histórica do Golpe Civil-Militar, atua-

\footnotetext{
2 Embora não sejam considerados nesse texto, podemos mencionar os vlogs, como um dos produtos da cultura digital, que reiteram esses procedimentos assentados em discursos sobre si. A definição de vlog que ainda está por se estabelecer, à principio, podemos destacar o gesto de filmar imagens e sons de si mesmo, construindo "narrativas" fortemente pessoais que vão desde confissões íntimas até as formas como os sujeitos lidam, por exemplo, com o vasto mundo do consumo. Os vlogs assumem o estatuto de "vídeo", são distribuidos e exibidos em plataformas digitais, sendo o YouTube, o meio mais recorrente.

3 As relações entre os projetos de esquerda dos realizadores e suas atividades junto ao programa Globo Repórter, da Rede Globo foram aprofundadas por Igor Sacramento, em Depois da revolução, a televisão. Cineastas de esquerda no jornalismo televisivo dos anos 1970 (2011).
} 
liza-se pelo que Fernão Ramos (2008) denomina a ética interativa/reflexiva, em que se advoga por procedimentos enunciativos de intervenção (entrevistas ou depoimentos) por parte do sujeito-da-câmera, podendo-se construir um modo particular de construção e de revelação do mundo ao espectador.

São esses recursos que fazem intervir, no desenvolvimento do documentário, falas pessoais em que o expediente da confissão, portanto onde a tônica dominante é modo pessoal de informar o relato, tenha papel bastante relevante. Nesse movimento, o ato de falar de si engendra formas de testemunhos e de memórias dolorosas, configurando-se em experiências pessoais ligadas às lutas dos camponeses e, sobretudo, decorrentes dos desdobramentos da tomada do poder pelos militares, algo que interrompeu as filmagens e trouxe consequências violentas a um grupo de pessoas que já tinha histórico de perseguições do latifúndio.

O que o filme restitui estabelece-se como um ritual de memórias traumáticas, manifestando as marcas da opressão nas vidas dos sujeitos. Entre as vozes articuladas, Elizabeth Teixeira é o destaque, sobretudo pela revelação de sua verdadeira identidade para a comunidade que vivia até então, gesto estimulado e atualizado pela presença da equipe do filme, no contexto da abertura política. Muitas vozes são ouvidas no filme, por exemplo, os filhos de Elizabeth, em entrevistas com Eduardo Coutinho, atestam para esse encaminhamento confessional dos relatos pessoais de suas dores profundas, em consequência de se verem distanciados de sua mãe, com a memória do assassinato do pai, em um conjunto de sofrimentos acumulados em face das consequências desagregadoras do Golpe na esfera familiar. Esse encontro singular e as formas de captura, são sintomáticos do quadro de mudanças radicais em devir no âmbito do documentário, sobretudo em relação à voz da mulher, que, a partir dos anos 1980, passar a ter um protagonismo destacado.
Assim, a questão central, neste texto, recai sobre o estudo de filmes documentários brasileiros marcados pela utilização da fala pessoal, por meio de arquivos de gravação, entrevistas e depoimentos, centrados em homens e mulheres adultos que narram sobre si. O foco são vídeos e filmes, em dois contextos, primeiramente na emergência das políticas identitárias, principalmente, dos anos 1970, 1980 e 1990, no Brasil, e as construções de subjetividade do cinema contemporâneo que reverberam e ressignificam essas práticas. Com isso, objetiva-se apresentar como a confissão realiza-se por diferentes estratégias e como isso permite refletir sobre as construções identitárias e subjetivas no campo documentário:

Os atores sociais não servem mais aqui, como testemunhas ou especialistas, exemplos ou ilustrações, nem mesmo como vozes de testemunhos autenticadores de histórias perdidas ou reprimidas. Apelos de caridade e gritos de indignação recuam; vozes diferentes, menos exortadoras do que pessoais, mais exploratórias do que conclusivas, falam" (NICHOLS, 1994, p. 2).

Embora constatemos que a recorrência à verborragia de experiências pessoais se dá em várias filmografias documentais, sabe-se que falar para a câmera e o gravador não significa necessariamente ter o domínio sobre a voz do filme. A voz é uma articulação posterior, "formada pela interação de todos os códigos de um filme" (NICHOLS, 2004, p. 50), resultado do trabalho de montagem de som e imagem, onde emerge o ponto de vista sobre o relato e, consequentemente, o atravessamento discursivo e seus efeitos de sentido. Assim, estou interessado nessas construções visuais e sonoras, muitas vezes centradas na articulação a partir de fragmentos corporais (uma voz over ou um corpo mutilado, tipo "cabeça falante"4) ou um corpo que fala, nessas vozes dos sujeitos que enunciam sobre suas experiências pessoais, podendo essas falas conviverem com outros materiais visuais e sonoros, além de seu próprio corpo ou voz registrados pela câmera.

\footnotetext{
4 A "cabeça falante" é um efeito desse aparato [testemunhal] específico, basicamente, com a cabeça, de acordo com a convenção, selecionada para o enquadramento e inclusão em uma sequência ordenada ou em um arquivo hipertextual. Na verdade, a "cabeça falante" (na qual a designação anatômica dos usuários é partir de um pescoço e ombros de apoio) só parece incorpórea porque o tronco, os quadris, as pernas e os pés foram desenquadrados pelo imperativo composicional do filme. E a cabeça parece estar sozinha (SARKAR: WALKER, 2010, p. 8)
} 
Podemos circunscrever, ética e esteticamente, esses modos de endereçamento das falas no testemunho e na confissão, ambos podem se entrecruzar, conceitualmente, mas há pontos de separação que devem ser destacados. Sobre como diferenciar o testemunho, podemos seguir com os apontamentos abaixo:

[...] o testemunho é uma força liminar preciosa, horrivel, facetada, relacionada institucionalmente, que, através de seu discurso sobre o outro e sua multiplicidade temporal, reflete sobre ações passadas para o presente e com propósitos futuros, constitui o simbólico humano - embora não necessariamente o ouvinte humano - como sintonizado política e historicamente. Há uma qualidade de abjeção nos testemunhos de sofrimento (onde eles existem), em que paradoxalmente, estranhamente e, necessariamente, eles destacam "o que a vida e a cultura humanas devem excluir para se sustentarem" (SARKAR; WALKER, 2010, p. 6).

Testemunhos estão relacionados às experiências de sobreviventes e aos traumas ligados às experiências históricas intensas. Nesse artigo, embora operações testemunhais atravessem algumas narrativas, o interesse articula-se em filmes em que manifestam o que denomino como o dispositivo confessional. São filmes que demarcam o campo político perpassado pela experiência pessoal, em uma associação entre o privado e o público, em um contexto que há inter-relação, em um primeiro momento, entre as políticas identitárias e a produção documental e, seguidamente, o endereçamento do documentário para o realce de construções de subjetividades, com outros atravessamentos e propósitos. O dispositivo confessional se atualiza em autobiografias, diários, nos modos do cinema direto/verdade, em filmes ensaios etc. Portanto, destaco o atravessamento de um mecanismo que coloca em evidência essas vozes pessoais, sendo formações discursivas que se modelam espaço-temporalmente na história.

A expressão "dispositivo confessional" será, primeiramente, definida nesse texto e em seguida, irei apresentar e discutir um conjunto de filmes de onde emergem essas práticas. Nessas relações, observo um campo de variações estratégicas e de efeitos de sentido de confissões que vão das afirmações e apelos identitários aos modos de afetividade entre os sujeitos (entrevistados e entrevistadores) e os dispositivos de som e imagem. Por fim, essas abordagens permitem avançar em relação ao repisado campo da representação, para partir para metodologias que possam discutir processos de produção dos sujeitos e suas demandas.

\section{Documentário: dispositivo confessional}

A princípio, documentários têm certa proximidade ao que Bill Nichols nomeia como os discursos de sobriedade, ou seja, "que podem ou devem alterar o próprio mundo, podem promover ações e desencadear consequências" (NICHOLS, 1997, p. 26). No entanto, a partir do documentário pode-se ir além de perspectivas mais verticalizadas em noções assentadas em "domínio e consciência, poder e conhecimento, desejo e vontade" (NICHOLS, 1997, p. 26) a que se destinam comumente as práticas da ciência, economia, política, relações internacionais, educação, religião, bem-estar social em que se constituem os discursos de sobriedade de vocação instrumental. Embora haja uma parcial participação na definição do documentário em relação aos discursos de sobriedade, pode-se, evocando-se outro texto do mesmo autor, alargar sua trama conceitual, sobretudo em uma acepção mais tensiva nas disputas discursivas que encetam relações de poder na imagem e pela imagem. Assim:

Tradicionalmente, a palavra documentário sugere plenitude e completude, conhecimento e fato, explicação do mundo social e seus mecanismos motivadores. Mais recentemente, porém, o documentário passou a sugerir incompletude e incerteza, lembrança e impressão, imagens de mundos pessoais e sua construção subjetiva. Uma mudança de proporções epistemológicas ocorreu. O que conta como conhecimento não é o que costumava ser. Para o eu coerente e controlador, que poderia fazer do mundo e dos outros seus objetos de escrutínio, agora é um só. Múltiplo (constituido de diversas subjetividades), dividido (consciente/ 
inconsciente), sedimentado (contendo o traço de eus passados e experiência anterior), o que o tal eu conhece e o que conhecemos de tal eu evita a pronta determinação. História e memória se entrelaçam; significado e ação, passado e presente, dependem um do outro distintamente. Documentário e ficção, ator social e outro social, conhecimento e dúvida, conceito e experiência compartilham fronteiras que inevitavelmente borram (NICHOLS, 1994, p. 1).

É importante assumirmos essa vastidão do vocabulário a que se liga o documentário, seja pela sua mobilização a uma epistefilia, ${ }^{5}$ o tangenciamento aos discursos de sobriedade, o acesso à realidade e, consequentemente, o desenvolvimento intrinseco de formas estéticas com o real, evocando o realismo e indo além dele, para alargamento das disputas conceituais. A hipótese aqui é relacionar o documentário, a partir dessas premissas, às chamadas tecnologias do eu, expressão cunhada por Michel Foucault (1990), para referir-se aos modos de governabilidade que operam na construção do sujeito, em que a confissão se articula como dispositivo dominante na constituição positivada do eu. Foucault examina isso em relação às ciências humanas. Nesse texto, estou conectando, consequentemente, a forma documentário como reguladora da experiência subjetiva. ${ }^{6}$

Confissões religiosas, médicas, juridicas, policiais, psicanalíticas têm sido as formas tradicionais pelas quais as pessoas organizam, via linguagem, seus relatos mais pessoais. Desde As Confissões, de Santo Agostinho - entre os séculos IV e V (1987) ao legado psicanalítico de Freud, tem-se a constituição de mecanismos reguladores da experiência, em que o ato de se confessar se articula pela exteriorização das experiências mais intimas e pessoais.

Em artigo intitulado "O que é um dispositivo", o filósofo italiano Giorgio Agamben (2005) organiza a trama conceitual sobre a palavra dispositivo, algo que considera estratégico para o pensamento do francês Michel Foucault. Assim, ele destaca três eixos de orientação para a compreensão do termo dispositivo: 1) um conjunto heterogêneo de elementos articulados em rede; 2) os dispositivos são estratégicos e inscrevem relações de poder; e 3) a ideia do dispositivo apresenta-se como uma episteme que assume função de verdade. ${ }^{7}$ Agamben, assim sintetiza o que seria um dispositivo:

Generalizando posteriormente a já amplissima classe dos dispositivos foucaultianos, chamarei literalmente de dispositivo qualquer coisa que tenha de algum modo a capacidade de capturar, orientar, determinar, interceptar, modelar, controlar e assegurar os gestos, as condutas, as opiniões e os discursos dos seres viventes. Não somente, portanto, as prisões, os manicômios, o panóptico, as escolas, as confissões, as fábricas, as disciplinas, as medidas jurídicas etc., cuja conexão com o poder é em um certo sentido evidente, mas também a caneta, a escritura, a literatura, a filosofia, a agricultura, o cigarro, a navegação, os computadores, os telefones celulares e - porque não - a linguagem mesma, que é talvez o mais antigo dos dispositivos, em que há milhares e milhares de anos um primata - provavelmente sem dar-se conta das consequências que se seguiriam - teve a inconsciência de se deixar capturar (AGAMBEN, 2005, p. 13).

No esteio de Agamben, o cinema e o audiovisual como um todo também estão incluidos na lista. Nessa direção, é o francês Jacques Aumont (2002), em A imagem, que vai discorrer amplamente sobre o dispositivo cinematográfico, juntamente

\footnotetext{
5 "A convenção documental dá origem a uma epistefilia. Postula uma entidade organizacional que possui informação e conhecimento, um texto que o transmite e um sujeito que irá obtê-lo. Aquele que sabe (o agente é geralmente do sexo masculino) vai compartilhar esse conhecimento com aqueles que querem saber; eles também podem ocupar o lugar do sujeito que conhece. O conhecimento, tanto ou mais que a identificação imaginária entre espectador e personagem ficcional, promete ao espectador sentimento de plenitude e autossuficiência. O conhecimento, como as figuras do eu ideal ou os objetos de desejo sugeridos pelos personagens de ficção de ficção, torna-se uma fonte de prazer que está longe de ser inocente. Quem somos nós que podemos saber alguma coisa? Em que consiste o conhecimento? O que sabemos e como usamos o conhecimento que temos são questões de importância social e ideológica." (NICHOLS 1997. p. 62-63).

6 Tomo como referência extratos do pensamento de Michel Foucault em suas etapas direcionadas para o estudo do poder e da governabilidade, ou seja, o recorte aqui é partir de seus investimentos nas questões da subjetividade ou o que ele preferia nomear como técnicas e tecnologias da subjetividade, é nesse âmbito que se inserem as relações entre documentário e o confessional.

7 A citação a seguir detalha sobre essa visão do autor: "1) É um conjunto heterogêneo, que inclui virtualmente qualquer coisa, linguistica e não linguística no mesmo título: discursos, instituições, edifícios, leis, medidas de segurança, proposições filosóficas etc. O dispositivo em si mesmo é a rede que se estabelece entre esses elementos. 2) O dispositivo tem sempre uma função estratégica concreta e se inscreve sempre em uma Relação de poder. 3) É algo de geral (um reseau, uma "rede") porque inclui em si a episteme, que para Foucault é aquilo que em uma certa sociedade permite distinguir o que é aceito como um enunciado científico daquilo que não e científico" (AGAMBEN, 2005, p. 9-10).
} 
com outros campos da imagem. Em sua definição, temos o conceito de dispositivo no campo cinemático entendido como o conjunto material e organizacional de "os meios e técnicas de produção das imagens, seu modo de circulação e eventualmente de reprodução, os lugares onde elas estão acessiveis e os suportes que servem para difundi-las" (AUMONT, 2002, p. 135). Aumont vai além, e sublinha que o dispositivo "regula a relação entre o espectador e suas imagens em determinado contexto simbólico", sendo o simbólico compreendido necessariamente em formações sociais específicas. Assim, revela-se que o dispositivo para cumprir sua tarefa de regulação deve, necessariamente, ser definido a partir de num determinado contexto social, dentro da história, e não como um ente que paira e sobrevive em uma espécie de universal delirante. Ainda com Foucault (2006, p. 70-71), estamos aproximando os termos dispositivo (agente regulador) e a confissão (e, também, o documentário):

[...] a confissão é um ritual de discurso onde o sujeito que fala coincide com o sujeito do enunciado; é também um ritual que se desenrola numa relação de poder, pois não se confessa sem a presença ao menos virtual de um parceiro, que não é simplesmente o interlocutor, mas a instância que requer a confissão, impõe-na, avalia-a e intervém para julgar, punir, perdoar, consolar, reconciliar; um ritual onde a verdade é autenticada pelos obstáculos e as resistências que teve de suprimir para poder manifestar-se; enfim, um ritual onde a enunciação em si, independentemente de suas consequências externas, produz em quem a articula modificações intrinsecas: inocenta-o, resgata-o, purifica-o, livra-o de suas faltas, libera-o, promete-lhe salvação (FOUCAULT, 2006, p. 70-71).

Crônica de um verão (1961), de Jean Rouch, disparou as possibilidades de confissões cinemáticas, trazendo para a tela o mundo privado de seus personagens, entrecruzando traumas de guerra, questões de gênero, classe e de raça por meio de relatos pessoais, a partir daí, o documentário fez desse dispositivo uma estratégia recorrente. Ainda no contexto da película, um filme tornou-se também emblemático no uso da confissão: Word is Out. Stories of Some of Our Lives (1977), dirigido por Nancy Adair, Andrew Brown e Rob Epstein. Trata-se de um filme inaugural sobre as revelações pessoais de gays e lésbicas sobre suas sexualidades, com destaque para a cena da saída do armário, como o título indica. $\mathrm{Na}$ década seguinte, outro filme, feito em 16 $\mathrm{mm}$, também causou impacto, refiro-me a Shoah (1985), de Claude Lanzman, em que as confissões de homens e mulheres judias se atualizam em forma de testemunhos que adensam a violência do nazismo. Diários e autobiografias são formas cinemáticas que atualizam as confissões, nessa direção, Ed Pincus (Diaries, 1971-1976, de 1982) e Ross McElwee (Sherman's March, 1986) estabeleceram-se como fortes referenciais na construção não ficcional de narrativas de si. E o nome de Marlon Riggs assinala uma produtiva interface entre as questões identitárias de raça, gênero e sexualidade, em um forte recorte poético para lidar com expedientes confessionais, em imbricamentos performáticos vigorosos, no marcante Tongues untied (1989).

Com a emergência e a ampla disseminação do vídeo, práticas confessionais explodiram em documentários. Sendo uma tecnologia de baixo custo e com facilidades de operação, ampliaram-se, com isso, os dispositivos de gravação e de reprodução da imagem em movimento, diversificando as demandas e as disputas pela imagem no audiovisual. Assim, em sincronia com esse fenômeno, as lutas e os movimentos sociais relacionadas ao feminismo, ao movimento de trabalhadores sindicalizados, comunidades rurais e periferia urbanas, os movimentos negros, indigenistas, LGBT etc. estavam articulados e em luta, o que fez convergir os interesses da indústria e dessas vozes dissidentes e reivindicatórias, tornando as décadas de 1980 e 1990 palco de disputas por representação ligadas às questões identitárias. Além disso, tanto o VHS quanto a fita K-7 tornaram-se formas de diários pessoais, convivendo com ou substituindo o papel e a caneta, compondo, portanto, um quadro complexo de apropriações de dispositivos de gravação de imagem e som, a serviço de demandas coletivas e pessoais. Seja do ponto de vista das representações e das reinvindicações coletivas no cam- 
po documentários, seja nas esferas individuais, falar de si para câmeras e gravadores passou a configurar como estratégia de luta, exigência, resistência e memória. Estritamente, no domínio dos documentários ligados às políticas de identidade, a dimensão do "pessoal é político", de herança feminista, enviesou o trabalho de realizadores para essa esfera.

Portanto, sendo o documentário também um discurso de sobriedade (NICHOLS, 1997, p. 33), um dispositivo que pode ser compreendido também como regulador da experiência, em relação aproximada aos discursos da ciência, do mundo jurídico, do jornalismo etc., com poder instrumental, de intervenção, e que atua, em relação direta e transparente com real e também prevê modos indiretos e opacos com o contingente, coloca-se a questão de definir qual o estatuto dessas imagens e sons que carregam essa herança e se expressam confessionalmente como forma dominante.

\section{Práticas confessionais documentárias em perspectivas ampliadas}

Para Bill Nichols (1997, p. 102), o "feminismo forneceu os instrumentos que não tinham o discurso documental", "instigou uma reconcepção radical da subjetividade e da política", e a "espectadora encontrou-se com uma experiência que reexaminava e recontextualizava os próprios rudimentos da experiência". Portanto, o teórico enfatiza que foi a partir da emergência desse movimento feminista ocidental, norte-americano e europeu e que ecoou internacionalmente, que o documentário ressignificou radicalmente suas práticas e abordagens. Vale ressaltar sobre a sincronia entre essa intensa agitação no âmbito de movimentos sociais e a emergência de equipamentos miniaturizados de gravação de imagem e som sincronizados.

As práticas confessionais documentárias são portadoras do modo participativo, na medida em que falar para a câmera e/ou para o gravador é condição imprescindivel para a manifestação da confissão. Tradicionalmente, seguindo um padrão estético, a configuração visual de uma confissão manifesta-se da seguinte forma:
O ângulo estático e fixo da câmera é constantemente um plano frontal (do médio ao close), dando a impressão de um retrato falante no qual o sujeito se dirige diretamente à câmera/ audiência, criando um relacionamento íntimo, envolvente e muitas vezes carregado emocionalmente entre o sujeito e o espectador (ATWELL, 2005, p. 222).

A partir do feminismo, as narrações de si tornaram o subjetivo político e isso também ativou outras práticas devotas nas relações com os marcadores de diferença, trazendo o falar de si para outras esferas, onde aparecem os marcadores de raça, classe, etnia, gênero e sexualidade. Sendo assim, essa relação dialógica é, também, constitutiva de uma revisão consciente dos modos pelos quais determinadas categorias eram/são subrepresentadas, o que faz com que a autoimagem confessional também recaia sobre formas de reflexividade e, também, de subversão à expressão canônica descrita acima. Finalmente, a atenção aos corpos e a valorização da construção do olhar permite constatar que a presença do modo performativo é caro ao nosso objeto de estudo. Os modos participativo, reflexivo e performativo agenciam as relações entre os sujeitos e o dispositivo, lembrando, porém que cabe ao analista verificar qual é o modo dominante na estruturação do relato. Aqui, não estou interessado em filmes que dispõe de aparatos confessionais à semelhança da reportagem policial (Noticias de uma guerra particular, João Moreira Salles e Kátia Lund, 1999), de filmes de investigação e denúncia (Falcão, meninos do tráfico, MV Bill e Celso Athayde, 2006) ou de narrativas estruturadas por dispositivos juridicos de confissão (Juizo, 2008; Justiça, 2004 - ambos de Maria Augusta Ramos) - sendo aqui o pessoal algo extraído de forma coercitiva e não só: são relatos em que os individuos se interessam por formar parte de um sistema.

Pioneiramente, tratando-se de uma realizadora brasileira, destacam-se os documentários de Rita Moreira, codirigidos com Norma Bahia, realizados em sua fase nova-iorquina, que trazia de forma pioneira, para o primeiro plano, mulheres e suas questões, em chaves diversas. Assim, Lesbian Mother (1972) é um documentário onde mães lésbicas 
relatam sobre suas saídas do armário enquanto ainda viviam casamentos heterossexuais e as consequências dessas decisões. Elas contam sobre suas experiências no modelo heteronormativo a que foram submetidas e a diretora deixa também seus filhos participarem dos registros, o que oferece um cruzamento complexo. Outras vozes também aderem a esse vozerio, desde a fala imponente de um psicólogo, até vários depoimentos violentamente lesbofóbicos. Compõe-se, assim, um painel de relatos e impressões pessoais sobre a maternidade lésbica, contrapondo-se à questão a partir da dominante heteronormatividade. Um filme militante, empenhado em construir um sentimento de comunidade, tal como se praticou amplamente nesse tipo de narrativa em que nos relatos intimos e pessoais trafegam conteúdo sobre questões de gênero e sexualidade, notadamente em que os territórios subjetivos se aliam a uma ampla comunidade identitária. She has a beard (1975) pertence à mesma série, e nele há uma radicalização da experiência sobre o corpo feminino. Assim, Forest Hope, uma artista feminista, deixa que os pelos de seu rosto cresçam à vontade e sai às ruas empunhando um microfone para coletar opiniões de mulheres sobre a questão dos pelos no rosto de mulheres, sendo um dos fortes subtextos a construção do feminino e as relações de opressão com o corpo. Contrapondo-se a essas intervenções públicas, há o relato em ambiente fechado, onde a personagem reflete profundamente sobre essas questões, onde a abstração nasce do depoimento que analisa uma vivência conturbada. Finalmente, em The apartment (1975/76), também da série, tem-se um documentário profundamente observativo, onde o elemento confessional é acionado pela câmera e o gravador que acompanha a reforma no apartamento da taxista Carol, executada por ela mesma. Nesse processo, ela se detém longamente sobre a cidade de Nova lorque, e acompanhamos a maneira como encara pessoalmente suas questões de gênero e sua intensa relação com o teatro.

Nos anos 1980, no Brasil, o exercicio da fala exerce muitas funções no campo documentário.
Em Quem Bom Te Ver Viva (1989), de Lúcia Murat, tem-se reunidos depoimentos de mulheres que foram presas e torturadas durante a ditadura militar. São imagens e sons de experiências de violência tornadas públicas poucos anos depois de iniciada a redemocratização. Essas entrevistas são intercaladas com delírios e fantasias, vividas pela atriz Irene Ravache, cuja personagem fictícia também foi presa e torturada, e luta para retomar o cotidiano. $O$ documentário se vale de um expediente ficcional e entrelaça histórias reais e uma imaginária, onde predominam as narrações de si sobre a participação nesse periodo obscuro da história brasileira. Aqui as confissões engendram um ponto de vista e uma identidade feminina sobre esses acontecimentos. Com isso, enfatizam-se as práticas específicas de violência sobre seus corpos e todas as formas de humilhação por parte de homens que inferiorizam mulheres, em uma hierarquia de gêneros incontestável. $O$ filme também objetiva restituir um sentimento de reconhecimento dessa luta e resistência e reiterar o gênero na construção dessa narrativa. Assim, o dispositivo confessional interveio como mecanismo de acerto de contas com o passado, por via do enfrentamento público de histórias traumáticas pessoais, vividas em ocasião de lutas coletivas, o que gera um campo de tensões e afetividades inesgotáveis.

Disse uma vez Lucia Murat, à propósito do filme:

Certo dia acordei com a ideia do que viria a
ser Que Bom Te Ver Viva, uma possibilidade de
trabalhar com documentário e ficção, ego e
superego, intimidade e distanciamento. Acordei
com a estrutura do filme sobre mulheres tor-
turadas na época da repressão, que depois fui
depurando. A estreia de Que Bom Te Ver Viva
foi muito funda, emocionante, não só para mim
como para todos que participaram do filme.
Foi uma sensação prazerosa; pela primeira
vez, depois de tanta violência sofrida, podia-
mos falar. A repercussão do filme foi enorme
(NAGIB, 2002, p. 324).

Também em 1989, outro documentário impactante foi lançado, Ori, dirigido por Raquel Gerber. O confessional no filme articula-se pela voz de Beatriz Nascimento, intelectual e poeta negra, ativista do movimento negro e uma importante 
articuladora teórica do feminismo negro. Ori é um dos trabalhos audiovisuais mais complexos de sua geração, tanto do ponto de vista de seu conteúdo, quanto do processo enunciativo que o atualiza. Levou 11 anos para ser realizado e apresenta uma reflexão muito original sobre as questões do negro na sociedade brasileira. A confissão aparece pela principal articuladora desses processos no filme. Raquel Gerber é acompanhada por Beatriz Nascimento que assume a primeira pessoa e expõe suas complexas ideias e teses sobre as questões raciais, em fina articulação com sua própria história pessoal e de sua família. Nessa fusão, entre o pessoal e o público está a tensão entre a invisibilidade e a visibilidade, em uma intrigada intersecção entre questões de gênero, classe e raça. Sob a voz de Beatriz e o olhar de Raquel, a questão da existência e da afirmação do negro pela imagem, atadas às histórias pessoais confessadas ligam-se a uma estrutura mosaicada que destaca o ressurgimento do movimento negro, ainda no final da ditadura, e acompanhamos Beatriz discorrer sobre suas teses que buscam outra história para os afro-brasileiros.

Embora a presença da confissão não seja tão enfática, Carmen Miranda, banana is my business (1994), de Helena Solberg, desenvolve-se por via de uma narração em primeira pessoa, sendo a voz da própria diretora, que não apenas organiza a trajetória de Carmen, como também, posiciona-se sobre essa biografia, deixando-se afetar por essa história, como confirma a narração de abertura:

Quando a Carmen morreu, eu era uma adolescente. Mas eu me lembro da multidão e da confusão nas ruas do Rio de Janeiro quando seu corpo chegou. Meus pais não me deixaram ir vê-la. Pessoas como meus pais sempre acham que quando o povo sai às ruas, seja qual for o motivo, é melhor ficar em casa. Foi assim que eu perdi minha única chance de ver a Carmen. [...] Eu encontrei esse retrato meu onde dá pra ver que eu não era um caso totalmente perdido. Se vocês podem imaginar umas frutas na minha cabeça, verão que as mãos estão na posição correta. [...] Eu comecei a ter uma série de sonhos bem estranhos com ela que me deixaram obcecada $[. . .]^{8}$.
E, também, no desfecho do documentário:

Eu termino minha história aqui, uma história
cheia de alegria e de tristeza também, como
a vida mesmo. Uma história talvez de recon-
ciliação, com Carmen e com nós mesmos. Eu
sei que ela foi embora, mas no meu sonho ela
voltou para ficar, para reafirmar o seu poder de
uma vez e por todas, para que seus seguidores
pudessem perpetuar o seu culto no universo
inteiro, e para que ela pudesse para sempre
ser parte da nossa mitologia9.

Ou seja, a confissão, para Solberg, funciona também como um mecanismo de ajuste de vozes políticas, resgate de memória e processo de criação, que afina relações profundas de identificação na construção da identidade da personagem e da autora.

Outra voz pioneira, surgida ainda no contexto do vídeo e que também assume uma linha mais engajada, independente e totalmente voltada para o circuito dos movimentos sociais é o coletivo feminista Comulher, com o destaque para Maria Angélica Lemos. No documentário Histórias Lésbicas (2003), dirigido por ela, a câmera acompanha de forma aproximada cinco depoimentos de mulheres que contam suas histórias pessoais diretamente ligadas à lesbofobia, em narrativas diferenciadas, o que resulta em um painel interseccional, que aprofunda a compreensão dos relatos. Nas confissões, elas relatam suas experiências pessoais ligadas ao convivio e às agressões familiares, às questões ligadas à deficiência física, à discriminação e ao preconceito racial e social, e às tensas relações com a justiça, em um caleidoscópio de opressões. No conjunto da produção audiovisual brasileira, é um documento marcante e assinala sua feitura militante e, principalmente, corajosa, ao criar um registro consentido e público de histórias em que o confessional transborda em histórias intimas de violência pautadas por questões de gênero e sexualidade da mulher lésbica.

Joel Zito Araújo também é um cineasta que carrega essa vivência da realização no contexto da redemocratização do Brasil. Em A negação do

8 Transcrição de trecho narrado em Carmen Miranda, banana is my business (1994), de Helena Solberg.

9 Transcrição de trecho narrado em Carmen Miranda, banana is my business (1994), de Helena Solberg. 
Brasil (2000), seu investimento artístico concilia o relato pessoal, memorialístico, e o relato de atrizes e atores para falar do racismo na teledramaturgia brasileira. Nos primeiros minutos, testemunhamos a performance do diretor por meio de sua voz over, em que suas memórias se conectam com o imaginário da recém implementada televisão brasileira e já anunciava a força das telenovelas. O filme reúne o diretor e a participação de artistas, por meio de depoimentos de Zezé Mota, Ruth Souza, Léa Garcia e outros, compondo um campo afetivo familiar. O elemento confessional disparador, a voz do diretor, faz-se ecoar comunitariamente, confluindo, assim, a experiência pessoal de um afrodescendente com as questões racistas que são enfrentadas no trabalho dentro e fora das telas.

Há outras maneiras de manifestação do confessional no documentário. Assim, reúno três filmes que chamam a atenção pelos usos de material de arquivo por parte de diretores que se apropriam de outras narrativas, costurando relatos a partir de fortes impressões pessoais deixadas pelos próprios personagens, todos já falecidos. Refiro-me a Meu Amigo Claudia (2009), de Dácio Pinheiro, Elena (2012), de Petra Costa e A paixão segundo JL (2014), de Carlos Nader.

Meu amigo Claudia conta a história da ativista, atriz, cantora e travesti Claudia Wonder, destacando sua aparição na pornochanchada, na cena musical pop paulistana, o seu comportamento e a sua postura política, a vida pessoal como transexual e o ativismo político. Claudia falava espontaneamente sobre si para câmeras de vídeo, marcou uma época e protagonizou lutas em favor da comunidade LGBT, sobretudo as transexuais e os travestis - os arquivos de suas falas e apresentações abundam no documentário. No filme, a colagem de arquivos e os vários depoimentos permitem uma costura histórica de seus percursos e as falas enfatizam a potência da memória. Uma memória dissidente, um sujeito sobrevivente, portanto, uma trama confessional interessada em uma personagem transexual e, consequentemente, o acesso às expressões raras dessa voz.
Elena é um documentário em que a realizadora Petra Costa, atualizada pela locução constante de sua voz e da imagem de seu corpo, realiza o que se poderia chamar um "autorrelato". o acontecimento narrativo é conduzido por essa figuração de uma primeira pessoa, e compreendido como a recuperação do passado de Elena, irmã da diretora, desde sua infância até momento em que ela comete suicídio no começo de sua juventude, nos anos 1990. A vida e a morte de Elena são relacionadas com momentos da vida de sua mãe e, principalmente, estabelece-se uma forte relação com a história de vida da diretora do filme e é a partir dessa imbricação intensa e profunda que o filme parece se justificar, desenvolver-se, sustentar-se e extrai daí sua força. Uma narrativa de mulheres, com parcos expedientes de vozes masculinas que são acionadas para o enfeixe narrativo. Do ponto de vista da expressão, o filme possui um processo de narração que reúne a voz da diretora do filme, cujo timbre se assemelha à voz de sua irmã Elena e essa voz que conduz o filme alinhava-se com uma trilha sonora fortemente inspirada para a construção de um campo dramático que busca afetar o espectador. Essa voz também se entrelaça à voz de Elena que, ao que tudo indica, não escrevia cartas ou diários escritos, e procurava registrar sua intimidade em fitas K-7. O documentário preserva um jogo fetichista com a imagem, atualizado pelo mascaramento conservador de seu jogo formal. Petra Costa, embora mascarada pelos artificios da linguagem, se enfrenta. Não faz da morte de sua irmã um acontecimento isolado de sua experiência e dai ganha sua força - ela também mata sua irmã, diante da câmera, para se refazer e redimensionar sua vida, seu gesto, corajoso por excelência, é um enfrentamento da morte no cinema e o tema do suicídio adentra o circuito confessional da narradora, em um processo que se converte em expiação.

Em A Paixão de J.L., Nader recupera fitas k-7 deixadas pelo artista plástico Leonilson, em que ele narrava sobre seu cotidiano, suas emoções, sua arte antes e durante a descoberta da AIDS em seu corpo. O testemunho, a partir da mani- 
festação da doença, é um registro de intensidade rara e as conexões que o documentário promove entre esse áudio fortemente emotivo e afetivo e a construção da poética do artista impõe-se como uma conjunção entre vida e obra, da perspectiva do diretor. Leonilson revela-se de maneira frágil e inocente, isso conflita com uma obra vigorosa e que fez diferença, e à medida que o filme avança, a dissimetria entre uma fala comum, insegura, banal e uma obra que caminha em um crescente é abismal. Mas é uma confissão, um projeto pessoal de um sujeito que criou esse registro, revelando ao público o quanto sua homossexualidade oscilava entre o romantismo, os segredos e as angústias. De qualquer forma, ali temos também um testemunho intimo que revela o que era ser homossexual em São Paulo nos anos 1990.

Filmes confessionais deixam marcas sobre modos e agenciamentos de construções individuais, são personagens de si que vêm à tona, sobretudo, nos casos em que a vida é obcecadamente registrada. Diários escritos e gravados deixariam transparecer que nessa esfera íntima estaria um projeto futuro de uma figura pública? Nos três últimos documentários, temos relatos intimos de artistas, coletados e organizados por outros artistas, desta vez cineastas que, a principio, enxergaram na escuta uma imagem possivel, revelada por jogos afetivos que jogaram luz sobre figuras individualizadas, mas com conexões fortes para suas épocas.

Ainda no recorte que conjuga observação, participação e performance, em Olhe para mim de novo (Kiko Goifman e Claudia Priscilla, 2011), o personagem Syllvio Luccio, um transexual homem, atravessa os estados do Ceará, Rio Grande do Norte, Paraíba e Pernambuco, e revela para a câmera suas histórias da transição e sua visão de mundo, acionando o mecanismo do depoimento que, por vezes, beira o confessional. Em várias sequencias, Syllvio é mostrado só, colocado à margem de rodovias e, muitas vezes, está acompanhado, conversando com pessoas distintas, sejam familiares, amores ou pessoas que encontra na peregrinação. Trata-se de uma estrutura bastante artificial de road movie, onde o percurso se constrói para a câmera e o sujeito dissidente vai ao encontro de outras pessoas na tentativa de potencializar reflexões sobre a diferença. Há um dado capturado dessa relação não realista, bastante artificial: o depoimento confessional não soa espontâneo e nota-se o preparo para exteriorizar de forma bastante organizada as narrativas de si.

Em Favela Gay (Rodrigo Felha, 2014), o diretor chama para o centro da narrativa as vozes negras LGBT, de favelas cariocas, em um passado recente, no contexto pós-UPPs (Unidade de Polícia Pacificadora), em comunidades cariocas, algo que demarca fortemente os posicionamentos aparentemente livres das câmeras nos espaços públicos das favelas retratadas. No filme, gays, lésbicas, transexuais e travestis circulam pelas ruas e vielas e os depoimentos são gravados em espaços abertos. Enfim, há um grande esforço em tornar público as falas e visível o livre trânsito dessas pessoas, para reforçar um clima de liberdade de expressão e oferecer um tratamento extremamente positivo em espaços tradicionalmente referidos como os lugares por excelência da violência e da pobreza extrema. São deslocamentos significativos que demarcam um posicionamento discursivo para uma construção afetiva sobre a comunidade LGBT, deslocando-se de estereótipos da favela. Onze pessoas diferentes que representam diferentes comunidades cariocas. Em Favela Gay torna-se interessante ver a trama social que se constrói, por meio das performances individuais ou a individuação estratégica dos entrevistados, que gera interesse e curiosidade por trazerem narrativas pessoais fortemente impregnadas com vivências familiares ou do bairro onde vivem.

Assim, da intimidade das relações familiares, das questões da aceitação, da luta pela sobrevivência, as relações com a prostituição e com o tráfico se configuram os temas da pobreza e da violência nesses sujeitos. Todos são representados de forma altiva, sem curvas dramáticas, nem oscilações de suas falas, sem pausas, sem silêncios e tensões. É forjada uma história que conecta distintas comunidades, comumente sinônimas do crime, da pobreza e da falta. No 
filme, as falas rumam para uma cronologia que aponta um passado não muito distante, em que a comunidade LGBT teve que impor-se pela força e pela presença, em todos os sentidos, e o presente do filme culmina em um estágio positivo de convívio social. Interessante notar essa rede entre as comunidades ativada pelo filme, algo como um território dentro do território, na megalópole.

\section{Sobre o falar de si em documentários: as performances confessionais}

No recorte de documentários apresentados, vemos os diferentes processos de articulação das falas de si funcionarem duplamente como espelho e janela. A dimensão especular diz respeito à maneira como, inevitavelmente, o sujeito, ao ser interpelado por alguém ou narrar sobre si, ou mesmo desempenhar essa atividade sozinho para dispositivos de gravação, fala primeiramente para si mesmo, organizando e convencendo-se do que está surgindo como ato de fala. Em uma outra perspectiva, há esse endereçamento para o mundo, uma vez concretizada a experiência de traduzir em palavras uma confissão de si mesmo (RENOV, 1996, p. 83). ${ }^{10}$

Há, em torno dos documentários e dos dispositivos de confissão, o acionamento de procedimentos e registros de narrativas pessoais, onde o mais intimo de si manifesta-se pelos sujeitos que enunciam suas histórias. A construção dessa imagem, seja por meio da relação do sujeito consigo mesmo, seja por meio da mediação com a alteridade sugere possibilidades e agendas diversas em torno dessas relações. $O$ fato é que se articulam mecanismos reguladores dessas experiências, em que se compreende, da maneira mais elementar, que essa irrupção interior passa, necessariamente por processos de organização que tornam esse contingente interior a serviço de outros códigos e outras demandas. Assim, o sujeito sujeita-se a um repertório de códigos que regulam seu corpo e sua voz, e esse conjunto é emoldurado pelos códigos do cinema, em uma outra estratégia de regulação, mas continua à serviço de outrem. O dispositivo da confissão opera, nesse sentido, como uma tecnologia reguladora de conhecimento e de poder, ao qual se pode nomear como performance ${ }^{11}$ confessional.

Seguindo esse raciocínio, nos documentários analisados, corpos e vozes de mulheres e homens, em relações ampliadas de gênero, sexualidade, raça atualizam-se em distintas performances; revelações e afirmações de corpos políticos são recorrentes; denúncias, resistências e lutas contra opressão; liberação e libertação dos sujeitos e de seus corpos; e testemunhos pessoais e construções de memórias coletivas agregam-se às várias estratégias de articulação da voz confessional, mas que sucumbem a mecanismos de regulação da própria experiência, via recursos cinemáticos.

Em um livro fortemente inspirador para as questões centrais desse artigo, e marcado por discussões de autores desde a filosofia política, à psicanálise, intitulado Relatar a si mesmo. Crítica da violência ética, Judith Butler afirma que "relatamos a nós mesmos simplesmente porque somos interpelados como seres que foram obrigados a fazer um relato de si mesmos por um sistema de justiça e castigo" (BUTLER, 2015, p. 22). A cena da interpelação unifica os autorrelatos, sendo o disparador necessário para que se inicie uma construção narrativa de uma verdade de si mesmo. Certamente, há algo a mais na lógica das narrativas pessoais, no âmbito do documentário, que amplia sobre a dimensão da justiça e do castigo, evidentemente, como atestam os filmes. Principalmente, quando notamos a forte presença de narrativas pessoais endereçadas e formatadas para as lógicas cinemáticas, em suas diferentes estratégias, dinamizando-se, formalmente, em diferentes modos expressivos. Isso faz pensar na fabricação provisória

10 Essa relação entre espelho e janela é trazida para o texto, tomando como referência fundamental o filme Crônica de um verão (1961) de Jean Rouch, citado pelo Michael Renov.

11 Utilizo o termo performance, a partir de Richard Schechner (2002, p. 2): "A noção subjacente é que qualquer ação enquadrada, apresentada, destacada ou exibida é uma performance". Do ponto de vista da teoria do cinema, Bill Nichols (1994) e Stella Bruzzi (2006), vislumbraram e aprofundaram, respectivamente, o entendimento sobre o que se concebe como documentário performativo. No presente texto, busco focar em como diferentes modos de confissão resultam em performances confessionais, portanto, situo-me no mesmo campo de estudos dos autores, explorando um viés não presente em suas considerações. 
do eu, entrando em um circuito do espetáculo que merece considerações à parte.

Considerando-se que o falar de si exige a interpelação, que aciona um mecanismo regulador da experiência para tornar público e organizar, via narrativa e linguagem, algo da vivência pessoal, o que desdobra, necessariamente, desse princípio da construção do eu-narrado incompleto e provisório é o espectro do fracasso:

Se a identidade que dizemos ser não nos captura e marca imediatamente um excesso e uma opacidade que estão fora das categorias da identidade, qualquer esforço de 'fazer um relato de si mesmo' terá de fracassar para que chegue perto de ser verdade. Quando pedimos para conhecer o outro, ou pedimos para que o outro diga, final ou definitivamente, quem é, é importante não esperar nunca uma resposta satisfatória. Quando buscamos a satisfação e deixamos que a pergunta permaneça aberta e perdure, deixamos o outro viver, pois a vida pode ser entendida exatamente como aquilo que excede qualquer relato que dela possamos dar. Se deixar o outro viver faz parte da definição ética do reconhecimento, tal definição será baseada mais na apreensão dos limites epistêmicos do que no conhecimento (BUTLER, 2015, p. 61).

De distintas formas, mulheres, negros, gays, lésbicas e um conjunto de marcadores interseccionais aparecem nos filmes e isso enforma e informa os documentários, desde as narrativas confessionais espontâneas (She has a beard), às relacionadas às dramatizações e aos arquivos (Que bom te ver viva e Carmen Miranda, Banana is my business), os diálogos com os arquivos ( $A$ Negação do Brasil), as gravações confessionais em dispositivos híbridos (Meu Amigo Claudia, Elena, A Paixão de J.L.), as formas empostadas e preparadas de falar de si (Olhe para mim de novo e Favela Gay). Nessas opções residem escolhas que necessariamente lidam com o sentimento de incompletude aferidos pelo dispositivo cinematográfico, a (in)capacidade de dizer integralmente sobre si e o olhar do diretor e disso derivam performances confessionais que compartilham dessas fissuras.

\section{Referências}

AGAMBEN, Giorgio. O que é um dispositivo?. Outra travessia, Florianópolis, v. 01, n. 05, p. 9-16, 2005.
AGOSTINHO, Santo. Confissões: De magistro (Do Mestre). 4. ed. São Paulo: Nova Cultural, 1987.

ATWELL, Lee. Word is Out and Gay U.S.A. In: ROSENTHAL, Alan; CORNER, John (org.). New Challenges for documentary. Manchester: Manchester University Press, 2005. p. 220-229.

AUMONT, Jacques. A imagem. 7. ed. Campinas: Papirus, 2002

BRUZZI, Stella. New documentary. Londres: Routledge, 2006. https://doi.org/10.4324/9780203967386.

BUTLER, Judith. Relatar a si mesmo: Crítica da violência ética. Belo Horizonte: Autêntica, 2015

FOUCAULT, Michel. História da sexualidade: A vontade de saber. 17. ed. Rio de Janeiro: Graal, 2006.

NAGIB, Lúcia. O Cinema da Retomada: Depoimentos de 90 Cineastas dos anos 90. São Paulo: Editora 34, 2002.

$\mathrm{NICHOLS}$, Bill. La representación de la realidade: Cuestiones y conceptos sobre el documental. Barcelona: Paidós, 1991

NICHOLS, Bill. A voz do documentário. In: RAMOS, Fernão (org.). Teoria contemporânea do cinema. São Paulo: SENAC, 2005. v. 2.

NICHOLS, Bill. Blurred Boundaries: questions of meaning in contemporary culture. Bloomington: Indiana University Press, 1994

NICHOLS, Bill. Speaking Truths with Film: Evidence, Ethics, Politics in Documentary. Berkeley: University of California Press, 2016. https://doi. org/10.1525/9780520964587.

RAMOS, Fernão. Mas afinal... O que é mesmo documentário. São Paulo: SENAC, 2008.

RENOV, Michael. Video Confessions. In: RENOV, Michael SUDERBUR, Erika. Resolutions: Contemporary video practices. Minneapolis: University of Minnesota Press, 1996. p. 78-101.

SACRAMENTO, Igor. Depois da revolução, a televisão: Cineastas de esquerda no jornalismo televisivo dos anos 1990. São Carlos: Pedro \& João Editores, 2011.

SARKAR, Bhasar, WALKER, Janet. (org.). Documentary Testimonies: Global Arquives of Suffering. Nova lorque e Londres: Routledge, 2010. https://doi. org/10.4324/9780203883419

SCHECHNER, Richard. Performance Studies: An Introduction. Londres: Routledge, 2002

XAVIER, Ismail. O cinema brasileiro moderno. São Paulo: Paz e Terra, 2001

\section{Gilberto Alexandre Sobrinho}

Doutor em Comunicação pela Universidade Estadual de Campinas (UNICAMP), em Campinas, SP, Brasil; professor do Departamento de Multimeios, Mídia e Comunicação, no Instituto de Artes, da Universidade Estadual de Campinas (UNICAMP), em Campinas, SP, Brasil. 
14/14 Revista FAMECOS, Porto Alegre, v. 27, p. 1-14, jan.-dez. 2020 | e-37567

\section{Endereço para correspondência}

Gilberto Alexandre Sobrinho

Universidade Estadual de Campinas

Instituto de Artes

Rua Elis Regina, 50

Barão Geraldo, 13083970

Campinas, SP, Brasil 